\title{
FUNDAMENTOS EPISTEMOLÓGICOS DAS RELAÇÕES CTS NO ENSINO DE CIÊNCIAS
}

\author{
EPISTEMOLOGICAL FOUNDATIONS OF STS RELATIONS IN SCIENCE \\ TEACHING
}

\author{
Luciana de Nazaré Farias ${ }^{l}$ \\ Werventon dos Santos Miranda \\ Silvio Carlos Ferreira Pereira Filho
}

\section{RESUMO}

Visamos a discutir os fundamentos epistemológicos das relações CTS (Ciência, Tecnologia, Sociedade) presentes em temas considerados socialmente relevantes no ensino de ciências. Consideramos que um dos principais objetivos do ensino de ciências numa abordagem CTS é o desenvolvimento da capacidade de tomada de decisões por parte dos estudantes, contribuindo, assim, para sua participação na sociedade. Embora haja uma busca por mudanças, as pesquisas têm mostrado que, nas escolas, os conhecimentos científicos ainda são apresentados aos alunos com status de conhecimento superior aos demais, como sendo averdade absoluta. Como resultados preliminares, destacamos que as pesquisas apontam para uma crescente valorização dos estudos CTS, que indicam a necessidade de explorar os conhecimentos sob um caráter mais amplo, buscando trabalhar ciências numa perspectiva curricular, cuja lógica de organização é estruturada em temas, com os quais são selecionados os conteúdos de ensino de ciências. Entretanto, o desenvolvimento da abordagem CTS nas escolas ainda é um desafio, pois a ciência e a tecnologia são abordadas de forma meramente ilustrativa, dissociadas das discussões de nosso tempo, em que paradoxalmente vivemos em constante contato com aparatos científicos e tecnológicos. É preciso contrastar as visões oficiais presentes nos sistemas de ensino e constituir fontes de visões alternativas para o ensino de ciências, buscando avançar no sentido de concepções de ciências e seu ensino, concernentes com o século XXI.

Palavras-Chaves: Epistemologia, Relações CTS, Ensino de Ciências.

\begin{abstract}
We aim to discuss the epistemological foundations of the STS (Science, Technology and Society) relations present in issues considered socially relevant in science education. We believe that a major goal of science education in a STS approach is the development of the capacity of decision-making by students, thus contributing to their participation in society. Although there is a quest for change, research has shown that in schools, scientific knowledge is still presented to the students with the status of a knowledge superior to others, as being the absolute truth. As preliminary results, we point out that studies show a growing appreciation of STS studies, which indicates the need for exploiting knowledge in a broader sense, seeking to work in a science curriculum perspective whose logic of organization is structured in

\footnotetext{
${ }^{1}$ Doutorandos em Educação em Ciências e Matemáticas pelo Instituto de Educação Matemática e Científica da Universidade Federal do Pará.

AMAZÔNIA - Revista de Educação em Ciências e Matemáticas V.9 - no 17 - jul. 2012/dez. 2012, p.63-75.
} 
topics, with which science education contents are selected. However, the development of the STS approach in schools still remains a challenge as science and technology are addressed merely in an illustrative way, separated from the discussions of our time, in which we paradoxically live in constant contact with scientific and technological apparatuses. It is necessary to contrast the official views present in educational systems and provide sources of alternative visions for science education, seeking to move towards conceptions of science and its teaching concerning the twenty-first century.

Keywords: Epistemology, STS Relations, Science Teaching.

\title{
RELAÇÕES CIÊNCIA-TECNOLOGIA- SOCIEDADE - HISTÓRICO E CONCEITUAÇÃO
}

\author{
Queremos saber o que vão fazer com as novas invenções \\ Queremos notícia mais séria sobre a descoberta da antimatéria \\ E suas implicações (...) \\ (Queremos saber - Gilberto Gil)
}

Um dos principais objetivos do ensino de ciências numa abordagem CTS (CiênciaTecnologia- Sociedade) é o desenvolvimento da capacidade de tomada de decisões por parte dos estudantes, contribuindo, assim, para sua participação na sociedade. Propostas de ensino numa abordagem CTS crítica incentivam os estudantes a questionar modelos e valores do desenvolvimento científico e tecnológico de nossa sociedade. Os estudantes são estimulados a perguntar, a quererem saber e problematizar as complexas inter-relações CTS, por meio da discussão integrada de conhecimentos científicos e tecnológicos e temas considerados socialmente relevantes.

Nesse sentido, no presente artigo temos como objetivo discutir aspectos epistemológicos no âmbito das relações CTS presentes em temas considerados socialmente relevantes no ensino de ciências. Para tanto, trazemos à consideração as contribuições de artigos que inter-relacionem em sua discussão dessa temática nos seguintes aspectos: epistemológicos, histórico e sociocultural, educacionais e políticos.

Diversas pesquisas da área de Educação em Ciências têm defendido a necessidade de reformulação e inovação das práticas docentes (GEHLEN, AUTH E AULER, 2008; AULER, 2007; SANTOS, 2008; MALDANER E ZANON, 2004; GONÇALVES, 2000; MONIZ DOS SANTOS, 1999) no sentido de superar o modo tradicional de passar conteúdos puramente informativos, fragmentados e descontextualizados nas aulas de ciências (MALDANER E ZANON, 2004). 
Em termos históricos, a partir da metade do século XX, tornaram-se evidentes questionamentos em relação ao desenvolvimento científico, tecnológico e econômico por não estarem atrelados, linear e automaticamente, ao bem estar social. Após euforia inicial com os avanços científico e tecnológico, nas décadas de 60 e 70, fatos como os conflitos bélicos ao redor do globo e a degradação ambiental geraram movimentos sociais que buscaram contestar os efeitos e direcionamentos da Ciência e Tecnologia (C\&T). Neste contexto histórico, emerge o denominado movimento CTS.

No Brasil, a inclusão da abordagem CTS nos cursos de ciências teve início da década de 70. Tais discussões se intensificaram no âmbito acadêmico, levantando a necessidade de uma participação maior da sociedade nas discussões sobre C\&T. (SANTOS e SCHNETZLER, 2000).

Buscamos levantar aspectos gerais que caracterizam a ciência numa concepção tradicional e em seguida, buscar nos deter a aspectos que possibilitem a compreensão da ciência integrada à tecnologia e à sociedade, bem como discutir fundamentos epistemológicos das relações CTS presentes em temas considerados socialmente relevantes no ensino de ciências.

A concepção tradicional de ciência a compreende como positivista, racional, neutra, asséptica, autônoma, baseada em um método único e infalível, o chamado método científico. Esta concepção de ciência é a mais difundida nas mídias, nas escolas e nas universidades de um modo geral (CHALMERS, 1993). Exemplifico: Quando uma propaganda de colchões quer evidenciar as qualidades destacadas de seu produto, corriqueiramente, recorrem à figura de autoridade máxima da ciência: "o cientista de jaleco branco" - afirmando que tal produto é o melhor por que foi "cientificamente testado e aprovado".

O conhecimento científico nesta perspectiva ganha um "status de verdade" absoluta, portanto inquestionável. Assim, o desenvolvimento científico historicamente é tido, muitas vezes como um processo regulado por um rígido código de racionalidade autônomo em relação a fatores sociais, políticos, econômicos, culturais, psicológicos, etc.

O movimento CTS surgiu, então, em contraposição ao pressuposto cientificista que valoriza a ciência em si, depositando uma crença cega em seus resultados. Nesta perspectiva, a ciência é vista como uma atividade neutra, de domínio exclusivo de um grupo de especialistas, que, de forma isenta e desinteressada, busca um conhecimento universal, cuja conseqüência ou uso inadequado não é de sua responsabilidade. 
O desenvolvimento do pensamento científico ao longo da história vem corroborando com a ideia de não-linearidades, mudanças de pensamentos e atitudes e revoluções científicas. Porém, quando paradoxalmente, analisamos a visão dominante de ciência transmitida nas escolas brasileiras e nos livros didáticos, encontramos um processo de conhecimento de ciências frequentemente neutro, imparcial, e por vezes pautado no positivismo (BRITO, SOUZA e FREITAS, 2008). Tal situação também é evidenciada em manuais para o ensino de ciências em Portugal, que apresentam uma visão distorcida de ciências, como nos diz Moniz dos Santos (1999, p.9), nos seguintes termos:

\begin{abstract}
Um corpo coerente de conhecimentos assépticos e imparciais sem interação com campos da tecnologia, da filosofia, da ética, da religião e da economia e deixando de lado importantes aspectos sociais. Não se mostra como controvérsias, crises e mudança de paradigmas afectam não apenas o campo científico mas a concepção que o homem tem do universo e do seu lugar no mesmo. A ciência permanece, pois, alheada da realidade, afastada do mundo em que se vive, com poucas conexões com problemas reais desse mundo. Não é apresentada como patrimônio cultural da humanidade, não se mostra a sua utilidade social, não se explica o seu papel na modificação do meio natural e social. Pelo contrário, ou surge como algo que não serve fora do contexto da escola, ou como algo que não se sabe para que serve ou para que se utiliza. Ou ainda, como algo que apenas serve para aceder a estudos posteriores.
\end{abstract}

Com relação aos documentos curriculares oficiais do Brasil já há evidencias de mudanças paradigmáticas, por exemplo, na importância atribuída à visão de ciência enquanto atividade humana, articulada ao contexto sócio- político-ambiental. Moniz dos Santos (2004) ao discutir sobre a necessidade de se trabalhar uma visão de ciência sem neutralidades, sem o "estigma" de verdade absoluta propõem que:

(...) Repensar o ensino das ciências e passar de uma "concepção de ensino de ciência pura" para a construção CTS de ensino das ciências. Produtos do conhecimento científico trabalhado de uma maneira que traga a sua validade cultural, para além da validade científica.

A atividade científica nessa perspectiva, não diz respeito exclusivamente aos cientistas e possui fortes implicações para a sociedade. Sendo assim, ela precisa ter um envolvimento social, ou seja, uma participação efetiva da sociedade dentro de uma perspectiva democrática que implica em envolver uma parcela cada vez maior da população nas tomadas de decisão sobre C\&T. Carvalho (2005, p.70) aponta um dos principais desafios da abordagem CTS: 
(...) É a exploração de questões sócio - ambientais à luz de suas relações com a ciência e com a tecnologia. Nesta vertente, o desafio principal reside em considerar as possíveis relações entre impactos ambientais e seus principais causadores que, normalmente, são os "produtos" dos artefatos científico-tecnológicos, os quais se mostram em forma de processos industriais, transporte, construções etc

As relações CTS evidenciam, valorizam a dimensão formativa e cultural do ensino de ciências. O ensino nessa concepção vai além da aprendizagem de conteúdos conceituais que interessam somente aos iniciados na ciência. É um ensino que não ignora os interesses sociais dos estudantes e contribui para o exercício da cidadania. Ao contrário de isolar, o ensino CTS busca que se estabeleçam interconexões entre as ciências naturais e os demais campos de conhecimento: tecnológico, comportamental, social, ético, etc. Segundo Bazzo (2003, p.125):

\begin{abstract}
(...) Os estudos CTS buscam compreender a dimensão social da ciência e da tecnologia, tanto desde o ponto de vista dos seus antecedentes sociais como de suas consequiências sociais e ambientais, ou seja, tanto no que diz respeito aos fatores de natureza social, política ou econômica que modulam a mudança científico tecnológica, como pelo que concerne às repercussões éticas, ambientais ou culturais dessa mudança
\end{abstract}

Trazer a discussão da abordagem CTS para o contexto escolar ainda é um desafio, pois comumente na escola ciência e tecnologia são abordados de forma meramente ilustrativa, sem relações com a vida do estudante, que paradoxalmente vive numa sociedade altamente influenciada por aparatos científicos e tecnológicos. Ricardo (2007) apresenta uma sugestão para inclusão da abordagem CTSA no contexto escolar:

(...) Sugere-se que a ciência e a tecnologia sejam assumidas como referências dos saberes escolares e a sociedade e o ambiente sejam tratados como o cenário de aprendizagem, do qual os problemas e questões sociais significativas surgiriam como temas a serem investigados com o suporte dos saberes científicos e tecnológicos.

Assim, para que se alcance um dos objetivos mais apontados por diversas pesquisas da área educacional em nosso país: a formação para a cidadania, incluindo, a capacidade de tomada de decisão está relacionado à solução de problemas da vida real que envolve aspectos científicos, sociais, tecnológicos, econômicos e políticos e discussões acerca da natureza da ciência, por meio de uma abordagem que articule ciência, tecnologia, sociedade e ambiente, concebendo a ciência como um processo social, histórico e não-dogmático; o que significa contribuir para a participação ativa dos estudantes na construção de uma sociedade democrática, Santos e Schnetzler (2000). 
Já em relação ao desenvolvimento de imagens não-dogmáticas de ciência, os cursos CTS apontam para discussões acerca do caráter provisório das teorias científicas. Com tal compreensão, os alunos poderiam avaliar as aplicações da ciência, levando em conta as opiniões controvertidas dos especialistas para ao contrário, com uma visão de ciência como algo absolutamente verdadeiro e acabado, os alunos terão dificuldade de aceitar a possibilidade de duas ou mais alternativas para resolver um determinado problema.

Alfabetizar, portanto, os cidadãos em ciência e tecnologia é hoje uma necessidade do mundo contemporâneo (SANTOS E SCHNETZLER, 2000, SANTOS E MORTIMER, 2002). Não se trata apenas de mostrar as maravilhas da ciência, como a mídia já o faz, mas de disponibilizar as representações que permitam ao cidadão agir, tomar decisão e compreender o que está em jogo no discurso dos especialistas (FOUREZ, 1995). Essa tem sido a principal proposição dos currículos com ênfase em CTS.

Consideramos relevante trazer para a discussão neste artigo o professor como representante da comunidade científica, sua ação docente e o processo de construção de conhecimento, como ação humana, e suas repercussões no contexto escolar. Como nos dizem Delizoicov, Angotti e Pernambuco (2002, p.34):

\begin{abstract}
A ação docente buscará construir um entendimento de que o processo de produção do conhecimento que caracteriza a ciência e a tecnologia constitui uma atividade humana, sócio-historicamente determinada, submetida a pressões internas e externas, com processos e resultados ainda pouco acessíveis à maioria das pessoas escolarizadas, e por isso passíveis de uso e compreensão acríticos e ingênuos; ou seja, é um processo de produção que precisa, por essa maioria, ser apropriado e entendido
\end{abstract}

Assim o movimento CTS no ensino de ciências postula uma espécie de reconceituação para o ensino da área. Trata-se de agregar de forma oportuna, a dimensão conceitual do ensino de ciências à dimensão formativa e cultural, fazendo interagir a educação em ciência com a educação pela ciência.

\title{
FUNDAMENTOS EPISTEMOLÓGICOS DAS RELAÇÕES CTS COMO ABORDAGEM DE ENSINO
}

Foi a partir de uma atividade na escola, a partir de uma palestra onde nós estudamos sobre relações ecológicas, eu me interessei em saber mais sobre os danos 
causados pelos cupins devido aos grandes problemas que estão tendo nas residências do município. (Lucas - estudante de $8^{\mathrm{a}}$ série do ensino fundamental ${ }^{2}$ )

A partir do estudo das relações ecológicas entre seres vivos, Lucas se interessou em investigar os danos causados pelos cupins devido aos grandes problemas que estão tendo nas residências do município. No ensino de ciências numa abordagem temática, os conteúdos são considerados como meios para a compreensão de temas socialmente relevantes (AULER e DELIZOICOV, 2001).

A abordagem temática consiste numa perspectiva curricular cuja lógica de organização é estruturada em temas, com os quais são selecionados os conteúdos de ensino. $\mathrm{Na}$ abordagem conceitual a lógica de organização é estruturada pelos conceitos científicos, com base nos quais se selecionam os conteúdos de ensino (DELIZOICOV, ANGOTTI e PERNAMBUCO, 2002, p. 189).

Na abordagem temática são discutidos aspectos sociais, culturais, ambientais, éticos, políticos e econômicos, denominados por Santos (2002) de aspectos sociocientíficos. A discussão de tais aspectos possibilita que diferentes visões de mundo possam circular nas aulas de ciências, tornando-as mais dialógicas (idem, 2002). Assim, as ideias dos estudantes não são ouvidas para serem simplesmente avaliadas como certas ou erradas, mas sim, colocadas em discussão no grupo, para que sejam questionadas, postas em contato com o discurso científico, ampliadas. Em tal prática dialógica assume-se a ciência como produção humana e em construção, que pode ser debatido em aula e integrado à vida dos estudantes. Assume-se a ciência como prática sócio-cultural fundamental no século XXI, em detrimento da concepção de ciência como conhecimento inquestionável e construído somente no passado.

Tais propostas têm resultado em contribuições significativas para o ensino de ciências, ao discutir a necessidade de renovação do ensino de ciências ${ }^{3}$ existente. Porém, o que observamos no contexto escolar, é que nas escolas, predomina ainda hoje, uma visão da ciência cujos pressupostos nortearam a ciência a partir do século XVII (BRITO, SOUZA e FREITAS, 2008).

Especificamente em relação ao ensino de biologia, tal ensino não fornece elementos para capacitar os alunos a analisar o conhecimento produzido pelas pesquisas científicas e tecnológicas (TRIVELATO, 1995). O ensino de Biologia tradicional, propedêutico,

\footnotetext{
2 Entrevista realizada em minha dissertação de mestrado: "Feiras de Ciências como oportunidades de (re) construção do Conhecimento pela Pesquisa", disponível em: http://www.repositorio.ufpa.br/jspui/bitstream/2011/1828/1/Dissertacao_FeirasCienciasOportunidades.pdf 3 Neste texto, a palavra Ciências engloba: Química, Biologia, Física, Matemática, etc. 
enciclopédico e memorialístico não fornece elementos de análise aos alunos e nem mesmo aos professores, neste artigo, versaremos sobre uma outra/nova epistemologia do conhecimentos, relacionando a abordagem CTS a um conhecimento mais amplo e crítico, como nos diz (ANGOTTI e AUTH, 2001):

Os estudos CTS têm atribuído um papel importante para os aspectos históricos e epistemológicos da ciência e a interdisciplinaridade na alfabetização em ciência e tecnologia. Eles indicam a necessidade de explorar os conhecimentos sob um caráter mais amplo, tendo uma reflexão crítica, embora vejam a dificuldade disso acontecer na prática. É preciso contrastar as visões oficiais presentes nos sistemas de ensino e constituir uma fonte de visões alternativas para o ensino

Sobre estas visões alternativas no ensino de ciências, vários pesquisadores e pesquisadoras da área de educação em ciências têm levantado questionamentos sobre o ensino de ciências nesta visão do século passado, buscando-se um entendimento das ciências como atividade social no sentido de perspectivas mais humanistas (SANTOS, 2004).

Neste sentido, acreditamos que no processo de produção do conhecimento todos os sujeitos envolvidos precisam ser ouvidos, num processo dialógico, levando em consideração seus anseios, suas perspectivas e motivações. A participação efetiva e ativa dos cidadãos é fundamental, para que os conhecimentos e as implicações sobre CTS não se restrinjam ao âmbito acadêmico das universidades, sem repercussões e mudanças efetivas na educação básica.

Embora, haja uma busca por mudanças, as pesquisas têm mostrado que nas escolas, os conhecimentos científicos ainda são apresentados aos alunos com status de conhecimento superior aos demais, como sendo a verdade absoluta. Os conteúdos são trabalhados de forma "estanque", sem considerar o contexto sócio, político, histórico e cultural no qual estão inseridos, tais reflexões são necessárias a fim de compreender como e porquê tal conhecimento surgiu numa determinada época e local. Para se entender o processo de produção do conhecimento científico, na sociedade contemporânea, exige-se que se considere a dimensão política desse conhecimento (BRITO, SOUZA e FREITAS, 2008, p.31).

Os conhecimentos científicos são tratados de forma fragmentada nas escolas e sem levar em consideração o contexto social em que os alunos estão inseridos, deste modo os conhecimentos científicos são apresentados aos alunos como sendo superiores aos demais conhecimentos, por que foi testado e comprovado, cabendo aos alunos decorá-los e evocá-los em provas e testes à guisa de nota (ARAGÃO, 2004). 
Na abordagem CTS os conteúdos de ensino não podem se restringir à lógica interna das disciplinas científicas, valorizando exclusivamente o conhecimento de teorias e fatos científicos, mas sim, reelaborando-os com temas sociais relevantes. Neste sentido, Freire (1987, p.57) acrescenta que:

\begin{abstract}
Conteúdos que são retalhos da realidade desconectados da totalidade em que se engendram e em cuja visão ganhariam significação. A palavra, nestas dissertações, se esvazia da dimensão concreta que devia ter ou se transforma em palavra oca, em verbosidade alienada e alienante. Daí que seja mais som que significação e, assim, melhor seria não dizê-la.
\end{abstract}

Considerar os conteúdos de ciências somente em seus aspectos conceituais, desconectados da totalidade em que se engendram, impossibilita o estabelecimento de relações com a tecnologia e a sociedade. Assim ao nos referirmos aos conteúdos escolares, estamos considerando-os em termos conceituais, procedimentais e atitudinais. Não coadunamos com a concepção "transmissiva" e "cumulativa" de ensino, pois tal concepção enfatiza a transmissão de conhecimentos, fazem com que os conteúdos desempenhem um papel de coluna vertebral no ensino e aprendizagem, atribuem aos alunos um papel essencialmente receptivo e concebem o professor como responsáveis pela transmissão de saber constituído (COLL, et al, 2000, p.10). Do mesmo modo, não concordamos com a concepção alternativa de ensino, apresentada como "progressista" ou "centrada no aluno", pois nesta concepção, tende-se, segundo Coll, et al, (2000, p.11) a:

(...) Destacar a importância da criatividade e da descoberta na aprendizagem escolar, a atribuir à atividade do aluno um papel decisivo na aprendizagem, a minimizar e a relativizar a importância dos conteúdos e a conceber o professor mais como um orientador da aprendizagem do que como um transmissor do saber constituído.

Assumimos uma interpretação radicalmente construtivista do ensino e da aprendizagem e sustenta, ao mesmo tempo, que os conteúdos desempenham um papel decisivo na educação escolar (COLL, et al, 2000, 11). Para que os conteúdos tenham significação para o aluno, é necessária, a nosso ver, uma mudança de postura dos professores de ciências e dos professores universitários, no sentido de incorporar às suas aulas, discussões sobre temas sociais relevantes, envolvendo os aspectos ambientais, culturais, econômicos, políticos e éticos relativos à C\&T; atividades de engajamento social dos alunos, por meio de ações concretas; e a discussão de atitudes e valores envolvidos. 
Podemos, dentro de um processo de ensino-aprendizagem no viés da abordagem CTS buscar as relações do assunto específico que estamos tratando com os conhecimentos oferecidos por outras Ciências. Assim, ao se trabalhar com o comportamento no trânsito, por exemplo, pode-se trazer a tona, além dos aspectos de cidadania que abrange direitos e deveres individuais e coletivos; temos a oportunidade de discutir o efeito do álcool no nosso organismo e sua evidencia nos acidentes de trânsito, o 'custo' financeiro e social de um acidente, a aplicação dos conceitos sobre movimento na formulação das regras de trânsito, entre outra tantas que podem ser relacionadas.

Mais do que fontes desencadeadoras de conteúdos conceituais, os temas constituem-se instrumentos para uma leitura integrada do mundo a partir das ciências (SOUZA e QUADROS, 2008). Freire (1999) utiliza a denominação tema gerador, que é entendido como o assunto que centraliza o processo de ensino-aprendizagem, sobre o qual acontecem os estudos, pesquisas, análises, reflexões, discussões e conclusões.

Fazendo a relação entre temas geradores e abordagem CTS (SANTOS, OLIVEIRA e CORDEIRO, 2009, p.164), acrescentam que:

\footnotetext{
Os temas tomam o caráter de temas geradores que envolvem situações contraditórias e que levam os indivíduos a se posicionarem diante deles e refletirem criticamente a realidade na qual estão inseridos, dando sustentação, assim, ou reestruturando a sua visão de mundo. $\mathrm{O}$ tratamento desse tipo de tema em sala de aula oportuniza a aproximação das reais condições de produção da Ciência e das suas conexões com a Tecnologia, com a Sociedade e com o Meio Ambiente
}

Portanto, consideramos de fundamental relevância a adoção de temas envolvendo questões sociais relativas à ciência e tecnologia no contexto escolar, que se inter-relacionem à vida dos alunos, bem como julgamos imprescindível o desenvolvimento de atividades de ensino de ciências e matemática, em que educandos tenham a oportunidade de discutir diferentes pontos de vista sobre a questão envolvida na busca da construção coletiva de possíveis alternativas de solução (SANTOS, 2000).

Freire $(1999,1987)$ propôs uma educação humanística, libertadora, tendo como foco principal a condição humana, que não se limita ao ensino de conteúdos conceituais. Sob esta perspectiva, a educação deveria ser mediada pelas questões existenciais dos alunos, o que na sua dinâmica de alfabetização corresponderia a um processo de codificação feito a partir de temas. 
Dentre os objetivos do ensino de ciências para a cidadania, destacando-se o desenvolvimento de valores e atitudes. Esses valores estão vinculados aos interesses coletivos, como os de solidariedade, de fraternidade, de consciência do compromisso social, de reciprocidade, de respeito ao próximo e de generosidade. Tais valores são, assim, relacionados às necessidades humanas, o que significa um questionamento à ordem capitalista, na qual os valores econômicos se impõem aos demais. A nosso ver, será por meio da discussão desses valores que contribuiremos na formação de cidadãos críticos comprometidos com a justiça social. (SANTOS, 2004, SCHNETZLER, 2000 e SANTOS, 2002).

Defendemos a ideia de uma educação em ciências como possibilidade de inclusão social. Inclusão que se constrói mais no sentido do questionamento acerca do uso e das implicações sociais dos conhecimentos científicos, do que na simples adequação dos sujeitos ao uso das novas tecnologias. BACHELARD (1978) acrescenta que todo conhecimento é resposta a uma dada questão. Se não houver questão, não pode haver conhecimento cientifico. Nada ocorre por si mesmo nada é dado. Tudo é construído.

Em síntese, assumimos a inclusão social a partir de uma perspectiva antagônica à ideia de educação científica como mero instrumento de manutenção da lógica de mercado vigente, como bem coloca Asmann (1998).

\section{CONSIDERAÇÕES FINAIS}

Neste estudo preliminar, visamos discutir os fundamentos epistemológicos das relações CTS presentes em temas considerados socialmente relevantes no ensino de ciências. Tais levantamentos apontam para uma crescente valorização dos estudos CTS, na área de ensino em Ciências e Matemáticas, principalmente nas duas últimas décadas, vem sendo atribuído a relação CTS, um papel importante para os aspectos históricos e epistemológicos da ciência e a interdisciplinaridade na alfabetização em ciência e tecnologia. Eles indicam a necessidade de explorar os conhecimentos sob um caráter mais amplo, buscando trabalhar ciências numa perspectiva curricular cuja lógica de organização é estruturada em temas, com os quais são selecionados os conteúdos de ensino.

O desenvolvimento da abordagem CTS nas escolas ainda é um desafio, pois a ciência e a tecnologia são abordadas de forma meramente ilustrativa, dissociadas das discussões de 
nosso tempo, em que paradoxalmente vivemos em constante contato com aparatos científicos e tecnológicos. É preciso contrastar as visões oficiais presentes nos sistemas de ensino e constituir fontes de visões alternativas para o ensino de ciências, buscando avançar no sentido de concepções de ciências e seu ensino, concernentes com o século XXI.

\section{REFERÊNCIAS}

ARAGÃO, R.M.R. Compreendendo a Investigação Narrativa de ações escolares de ensino e de aprendizagem no âmbito da formação de professores. $22^{a}$ Reunião Anual da ANPEd, Caxambu:2004<disponível em: www.anped.org.br/27/gt08/t0818.pdf. acessado em:15/10/2005>.

ASSMANN, H. Reencantar a educação: rumo à sociedade aprendente. Petrópolis, RJ: Vozes, 1998.

AULER. D. Enfoque ciência tecnologia sociedade: pressupostos para o contexto brasileiro. Ciência \& Ensino, vol. 1, número especial, novembro de 2007.

AULER. D e DELIZOICOV. D. Alfabetização científico-tecnológica para quê? . ENSAIO - Pesquisa em Educação em Ciências, Volume 03, Número 1 - Jun 2001.

ROSELI P. SCHNETZLER. Quimica . Nova, Vol. 25, Supl. 1, 14-24, 2002.

BACHELARD. G. A Filosofia do Não. São Paulo: Coleção abril Cultural. Coleção Os Pensadores, 1978

BAZZO, W. A.; VON LINSINGEN, I; PEREIRA, L. T. V. (Eds). Introdução aos estudos CTS (Ciência, Tecnologia e Sociedade. Madrid: OEI, 2003. Capítulo 4: O que é Ciência, Tecnologia e Sociedade?

BRITO,D.L; SOUZA M.L e FREITAS, D. Formação inicial de professores de ciências e biologia: a visâo da natureza do conhecimento científico e a relação CTS. INTERACÇÕES NO. 9, PP. 129-148 (2008).

CARVALHO, W. L. P. Cultura científica e cultura humanística. 2005. Tese (Livre Docência) Faculdade de Engenharia de Ilha Solteira, Universidade Estadual Paulista, Ilha Solteira.

CHALMERS, A. F. O que é Ciência Afinal? Ed. Brasiliense, 1993.

COLL, C. e colaboradores. Os conteúdos na reforma: ensino aprendizagem de conceitos, procedimentos e atitudes. Porto Alegre: Artes Médicas, 2000.

DELIZOICOV, D.; ANGOTTI, J. A.; PERNAMBUCO, M. M. Ensino de Ciências - fundamentos e métodos. São Paulo: Editora Cortez, 2002. Didáctica de las Ciências, Barcelona, pp. 2559-2562. In: http://ensciencias.uab.es/congreso09/numeroextra/art-2559-2562.pdf.

FOUREZ, G. O método científico: a comunidade científica. In: A construção das ciências. São Paulo: UNESP, 1995, p.91-102.

FREIRE, P. Pedagogia da Autonomia: saberes necessários à prática educativa. Rio de Janeiro: Paz e Terra, 1999.

Pedagogia do Oprimido. Rio de Janeiro: Paz e Terra, 1987.

GEHLEN, S.T, AUTH, M.A E AULER, D. Contribuições de Freire e Vygotsky no contexto de propostas curriculares para a Educação em Ciências. Revista Electrónica de Enseñanza de las Ciências. Vol. $7 N^{o} 1$ (2008). 
GONÇALVES, T. V.O. Ensino de Ciências e Matemática e formação de professores: Marcas da diferenças. Tese (doutorado) - Universidade Estadual de Campinas, Faculdade de Educação Campinas, SP, 2000.

MALDANER, O.A, ZANON, L.B, Situação de estudo: uma organização do ensino que extrapola a formação disciplinar de ciências, in: Educação em Ciências- Produção de currículos e formação de professores, Ed. Ijuí, 2004.

MONIZ DOS SANTOS, M.E.V. Desafios Pedagógicos para o Século XXI. Ed. Livros Horizonte, Lisboa, 1999.

. Educação pela ciência e educação sobre ciência nos manuais escolares. Revista Brasileira de Pesquisa em Educação em Ciências. Vol. $1 N^{\circ} 4$ (2004).

SANTOS, P.G. F; OLIVEIRA, E.R e CORDEIRO, M.A.M. Inserção do enfoque CTSA em uma sala de aula eja através da abordagem temática. I Mostra de Atividades de Extensão da UNESP, USP, São Paulo, 2009. In: http://prope.unesp.br/xxi_cic/27_02030196100.pdf

SANTOS, W.L.P.; MORTIMER, E.F. Uma análise de pressupostos teóricos da abordagem C-T-S (Ciência - Tecnologia - Sociedade) no contexto da educação brasileira. Ensaio - Pesquisa em Educação em Ciências, v. 2, n. 2, p. 1-23, dez. 2002

NOVEMBRO 2004

, Desenvolvimento de atitudes e Valores, In: Química Nova na Escola, № 20,

SANTOS, W. L.P dos. e SCHNETZLER, R.P. Educação em Química: Compromisso com a cidadania. Ijuí: Ed. UNIJUÍ, 2000.

SANTOS, W.L.P. Aspectos sócio-científicos em aulas de química. Tese (Doutorado), Faculdade de Educação, UFMG, Belo Horizonte, 2002.

SOUZA, A.L e QUADROS, A.L. O lixo plástico: discutindo algumas concepções apresentadas por estudantes. XIV Encontro Nacional de Ensino de Química (XIV ENEQ). In: http://www.quimica.ufpr.br/eduquim/eneq2008/resumos/R0203-2.pdf

TRIVELATO. S. L. F. __ Ensino de Ciências e o Movimento CTS (Ciência /Tecnologia/ Sociedade). In: $3^{a}$ Escola de Verão para professores de Prática de Ensino de Física, Química e Biologia. Coletânea, Faculdade de Educação da Universidade de São Paulo, 1995.

RICARDO, E.C. Educação CTSA: obstáculos e possibilidades para sua implementação no contexto escolar. Ciência \& Ensino, vol. 1, número especial, novembro de 2007 